\title{
Urinary level of interleukin-1alpha and interleukin-6 in patients underwent extracorporeal shock wave lithotripsy
}

\author{
Mohsen Rajabnia Chenari ${ }^{1}$, Faramarz Fazeli2* ${ }^{*}$, Mehdi Jahantigh ${ }^{3}$, Javid Dehghan ${ }^{4}$, Amin Zarghami $^{5}$, \\ Mohammad Bahadoram $^{6,7}$, Ali Ghorbani ${ }^{6}$, Sajedeh Mirshahvalad ${ }^{8}$ \\ ${ }^{1}$ Department of Internal Medicine, Kurdistan University of Medical Sciences, Kurdistan, Iran \\ ${ }^{2}$ Department of Urology, Zahedan University of Medical Sciences, Zahedan, Iran \\ ${ }^{3}$ Department of Pathology, Zahedan University of Medical Sciences, Zahedan, Iran \\ ${ }^{4}$ Department of Community Medicine, Zahedan University of Medical Sciences, Zahedan, Iran \\ ${ }^{5}$ Iranshahr University of Medical Sciences, Iranshahr, Iran \\ ${ }^{6}$ Chronic Renal Failure Research Center, Department of Internal Medicine, Faculty of Medicine, Ahvaz Jundishapur University of \\ Medical Sciences, Ahvaz, Iran \\ ${ }^{7}$ Student Research Committee, Faculty of Medicine, Ahvaz Jundishapur University of Medical Sciences, Ahvaz, Iran \\ ${ }^{8}$ Student Research Committee, Babol University of Medical Sciences, Babol, Iran
}

\section{A R T I C L E I N F O}

Article Type:

Original

\section{Article History:}

Received: 30 December 2016

Accepted: 19 March 2017

Published online: 4 April 2017

\section{Keywords:}

Lithotripsy

Interleukins

Urinary calculi

Inflammation

\begin{abstract}
A B S T RACT
Introduction: Extracorporeal shock wave lithotripsy (ESWL) was established as a dramatic procedure in the treatment of urinary stones. According to the growing utilization of ESWL as a major method of urinary stone, management and the reports have been reported based on renal tissue damage.

Objectives: We decided to examine the severity of ESWL-induced renal tissue damage and its related factors by monitoring the urinary levels of cytokines.

Patients and Methods: In this study, the urinary samples of 32 patients with urolithiasis were taken before, 24 hours and 14 days after ESWL and interleukin-1a (IL-1a) and interleukin- 6 (IL-6) levels were measured by enzyme-linked immunosorbent assay (ELISA) method.

Results: Our findings indicated that there was a significant difference between the urinary levels of both IL-1a and IL- 6 in 14 days before and after ESWL.

Conclusion: According to our results, ESWL leads to an inflammatory process in the urinary tract and the inflammation have continuously increased up to 14 days after procedure.
\end{abstract}

Implication for health policy/practice/research/medical education:

Findings of the current study highlighted the underlying inflammatory process following extracorporeal shock wave lithotripsy (ESWL) procedure and can be a good sample for further investigations.

Please cite this paper as: Rajabnia Chenari M, Fazeli F, Jahantigh M, Dehghan J, Zarghami A, Bahadoram M, et al. Urinary level of interleukin-1alpha and interleukin-6 in patients underwent extracorporeal shock wave lithotripsy. J Renal Inj Prev. 2017;6(3):231-235. DOI: 10.15171/jrip.2017.43.

\section{Introduction}

Urinary stone is the third common urologic disease. Fifteen percentage of the general population will develop the disease during life span (1). Extracorporeal shock wave lithotripsy (ESWL) was primarily used for medical intentions in the 1980s and established the dramatic effect on the treatment of urinary stones. Today, it is estimated that $90 \%$ of upper urinary tract stones could be managed by this method with a success rate of $68 \%-86 \%(2-4)$. The access to urinary stone depends on several major factors including size, location and type of calculi $(5,6)$. Not only ESWL is a major treatment of stones below $2 \mathrm{~cm}$, but stones less than $10 \mathrm{~mm}$ have also been mostly affected. However, stones less than $10 \mathrm{~mm}$ in diameter are mostly affected by ESWL. The major impact of ESWL is on the stones located in middle calyx, upper calyx and renal pelvis respectively. Distal ureter and bladder are placed in the latter positions. Among stones of different types, uric acid and struvite are 
the most sensitive stones against ESWL (7-9). Although it is considered as a noninvasive method, ESWL as well as any other treatment has its own complications which causes acute and rarely chronic damages including renal damage, renal colic pain for more than 24 hours, transient hydronephrosis and dermal ecchymosis. It can also lead to urinary tract infection, hypertension and hematuria $(10,11)$. The exposure of shock waves for the purpose of destructing urinary calculi could have been undesirable effects on the soft tissues and vascular system of urinary tract. Subsequently, it could lead to inflammation and tissue damage $(12,13)$.

Several pro-inflammatory markers have been utilized in urological practices in order to gain an accurate and detailed diagnosis of renal damage. One of these methods is the measurement of urinary cytokines. Cytokines are a category of either protein molecules or soluble glycoproteins. The role of these signaling molecules is communication between immune cells or other cells. They regulate inflammatory and immune responses (14). Interleukin-1a (IL-1a) and interleukin-6 (IL-6) are used to call pro-inflammatory cytokines due to their role in the inflammatory process. Therefore an increase in the level of these elements indicates the presence of inflammation. Given the essential role of these molecules in the inflammatory responses, they are extensively used to evaluate cellular damage $(15,16)$.

\section{Objectives}

According to the growing application of ESWL as a major method of urinary stones lithotripsy and the reports concerning the probable renal tissue damage, we decided to investigate the severity of ESWL-induced renal tissue damage (inflammatory response to ESWL) by the evaluation of IL-1a and IL-6.

\section{Patients and Methods}

This prospective observational study was conducted on patients with a history of urinary stone symptoms referred to Ali-ebne-Abitaleb hospital in Zahedan, South-East province of Iran.

\section{Patients}

Participants were collected with systematic randomized sampling method. The demographic data of patients (age and sex) were recorded. Once taking history, they were all examined. Routine tests and imaging was performed for all patients. ESWL candidates were those with urinary stones ( 5 to $20 \mathrm{~mm}$ ) diagnosed by history, physical examination, laboratory and imaging tests. All of them were included in our study $(17,18)$. The exclusion criteria was essential hypertension, active bleeding disorders, serum creatinine above $3 \mathrm{mg} / \mathrm{dL}$, urinary obstruction distal to the stone, urinary tract abnormalities (horseshoe kidney, displaced kidney, and extra-kidney), the history of colicky or renal lodge pain or taking analgesics or any other antiinflammatory or immunosuppressant in previous week and existence of any infection (21-25).

\section{Measurements and procedures}

A total of 32 patients were included to the study. All the patients were treated by ESWL after receiving parenteral sedative (Ketamine $2 \mathrm{mg} / \mathrm{kg}$ IV or Pentazocine 0.5-2 mg/ $\mathrm{kg})(20,21)$. Patients were treated by using the device (Dornier Compact Sigma, Med Tech, Kennesaw, GA, USA). The whole aspects of treatment including number of shock waves, voltage of device, and duration of treatment were recorded. Approximately 2200-4000 shock waves at the range of $10-20 \mathrm{kV}$ were applied equally. To investigate cytokines, urine samples were taken before ESWL, 24 hours and 14 days after it. Urine samples were obtained by standard methods and were studied by using enzymelinked immunosorbent assay (ELISA) (ASYS, Germany) for measuring the IL-1 and IL-6 levels by Orgenium kit of Finland. The participants were instructed not to use any medication without consulting with the researcher urologist.

\section{Ethical issues}

The study protocol was in accordance with the declaration of Helsinki and was approved by the Ethics Committee of Zahedan University of Medical Sciences. All participants gave their informed written consent to enter the study (\# 1202).

\section{Statistical analysis}

Collected data were analyzed by SPSS 18 software (Chicago, IL). The Kolmogorov-Smirnov test was used to evaluate the normality of the data. Quantitative data were expressed as mean \pm standard deviation (SD). Urinary level of ILs were compared before and after performing ESWL by paired $t$-test. Independent $t$-test was utilized for presence or absence of significant fluctuation of interleukin levels based on type, stone position, stone size, and involved side. Differences were considered statistically significant when $P<0.05$.

\section{Results}

The mean age of the participants was $37.8714 .38 \pm$ years (range from 19 to 77 ). Nineteen patients (59.37\%) were males and 13 were females (40.62\%). Of the cases, $46.8 \%$ had stones sized $10 \mathrm{~mm}$ or less and others presented with stones larger than $10 \mathrm{~mm}$. Mean size of stone was $11.34 \pm 3.15 \mathrm{~mm}$ (7 to $19 \mathrm{~mm}$ ). The stones were located in right urinary tract in 15 (46.8\%) patients and 17 (53.1\%) of them had left-sided stones in their urinary tract. Renal stones were detected in $22(68.7 \%)$ and ureter stones in $10(31.2 \%)$ cases. The difference between inflammatory elements with several baseline parameters including sex, location of stones in the urinary tract, size of the stones and involved side were not significant (Table 1).

\section{Serum levels of IL-1a}

The mean urinary level of IL-1a measured before the ESWL was $5.94 \pm 5.44 \mathrm{pg} / \mathrm{mL}$. Mean urinary levels of IL-1a 24 hours and 14 days after ESWL were $7.88 \pm 7.14$ $\mathrm{pg} / \mathrm{mL}$ and $10.60 \pm 10.33 \mathrm{pg} / \mathrm{mL}$, respectively (Figure 1). 
Table 1. The comparison between the mean urinary level of IL-1a and IL-6 in the study interval

\begin{tabular}{|c|c|c|c|c|}
\hline & $\begin{array}{c}24 \text { hours after ESWL/before } \\
\text { ESWL index }\end{array}$ & $P$ value & $\begin{array}{c}14 \text { days after ESWL/ } 24 \text { hours } \\
\text { after ESWL index }\end{array}$ & $P$ value \\
\hline \multicolumn{5}{|c|}{ Gender (male/female) } \\
\hline IL-1a & 1.77 / 1.70 & 0.848 & $1.33 / 1.60$ & 0.444 \\
\hline IL-6 & $3.52 / 2.74$ & 0.620 & $2.25 / 4.69$ & 0.182 \\
\hline \multicolumn{5}{|c|}{ Location (kidney/ureter) } \\
\hline IL-1a & $1.66 / 1.93$ & 0.522 & $1.67 / 0.925$ & 0.056 \\
\hline IL-6 & $3.44 / 2.68$ & 0.650 & $3.79 / 2.03$ & 0.367 \\
\hline \multicolumn{5}{|c|}{ Size $(\leq 10 \mathrm{~mm} / 10 \mathrm{~mm}<)$} \\
\hline IL-1a & 1.99 / 1.53 & 0.243 & $1.33 / 1.53$ & 0.578 \\
\hline IL-6 & $2.58 / 3.80$ & 0.405 & $2.58 / 3.82$ & 0.498 \\
\hline \multicolumn{5}{|c|}{ Side (right/left) } \\
\hline IL-1a & 1.69 / 1.79 & 0.807 & 1.32 / 1.54 & 0.530 \\
\hline IL-6 & $2.99 / 3.39$ & 0.795 & $2.45 / 3.94$ & 0.396 \\
\hline
\end{tabular}

Repeated measures revealed significant increase between the levels of IL-1a level before ESWL, 24 hours and 14 days after the procedure $(P<0.001)$.

\section{Serum levels of IL-6}

The mean urinary level of IL-6 measured before ESWL was $5.82 \pm 4.64 \mathrm{pg} / \mathrm{mL}$. Mean urinary levels of IL-6 24 hours and 14 days after ESWL were $14.33 \pm 14.01 \mathrm{pg} / \mathrm{mL}$ and $44.67 \pm 32.97 \mathrm{pg} / \mathrm{mL}$, respectively (Figure 1). Repeated measures revealed significant difference between the levels of IL-1a level before ESWL, 24 hours and 14 days after the procedure $(P<0.001)$.

\section{Discussion}

In this study, urinary levels of IL 1-a and IL-6 were assessed before the operation, 24 hours and 14 days after ESWL. Increased urinary levels of both interleukins indicated a significant difference through the study. Our findings revealed that ESWL causes inflammation in the urinary system and this rising trend of inflammation lasts within 14 days.

Complications of ESWL including induced inflammation have been attracted great attention in previous studies.

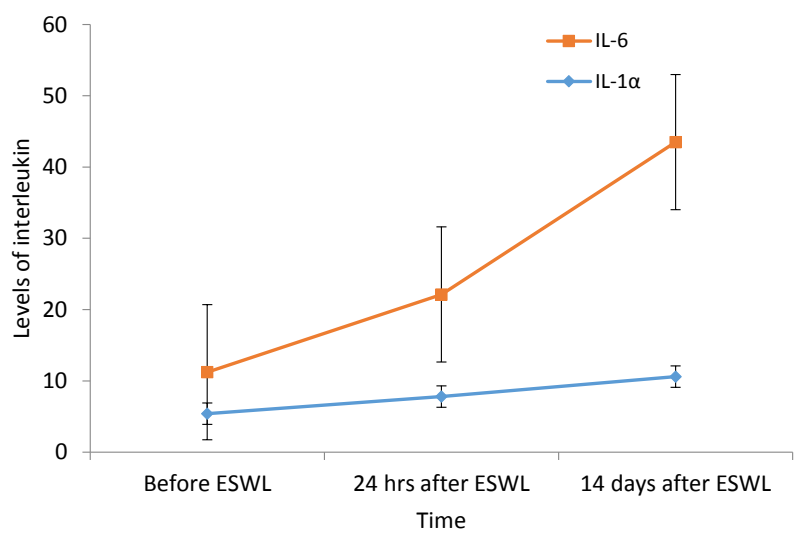

Figure 1. The mean value of urinary levels of ILs, before, 24 hours, and 14 days after ESWL.
Goktas et al similarly measured the urinary levels of IL$1 \mathrm{a}$ and IL-6 to examine the presence of ESWL-induced inflammation and the severity of the process. They reported a significant increase in the level of IL-6 during early phase ( 24 hours after ESWL). They also found the same results about levels of IL-1a during a 14-day period (12). Also, Dundar et al revealed a significant increase in the level of IL-1a in the early phase (24 hours after ESWL) and IL-6 over a 14-day course in patients underwent ESWL (22). There was previously a question whether the levels of IL- 6 and IL-1a in stone formers could be utilized as a predictive factor of stone formation; but there were no supportive evidences $(\underline{23})$. The difference in the results of various studies may be due to the difference in race, type of equipment used, and skill level of surgeon.

In several studies, other markers had also been used to investigate the inflammation and renal damage after ESWL. Sarica et al used urinary and serum levels of nitrite and adrenomedullin to evaluate the presence and severity of ESWL-induced renal damage. Their finding indicated the increasing levels of both markers 24 hours after ESWL (13). The inflammation induced by ESWL can be the consequence of unintentional lithotripsy shock waves exposure to the surrounding tissue. These waves can lead to damage to the renal artery directly. It may also cause an inflammatory response, known as ESWL-induced nephritis $(\underline{12}, \underline{13})$.

Considering the importance of this issue, we studied many parameters neglected in other studies including sex, size, location and side of stone in urinary tract. We assumed that the differences had to be significant in different locations and size of stones according to the more tissue mass in kidney compared to ureter, further amount of shock wave and wider area of exposure in urinary tract tissues for lithotripsy of larger stones. However, we did not notice any significant difference in any of our variables. This finding may suggest the hypothesis that the extent and severity of ESWL-induced inflammation does not vary in different sexes, sizes, locations and the involved 
side. The probable explanation for these findings might be the standard ESWL with the same dose of shock wave exposure to our patients' urinary tract tissue in spite of age and sex. Our conclusion should be interpreted with caution because of small study population. Nevertheless, in several studies, these variables concerning ESWLinduced inflammation have not been fully investigated $(12,13)$; in comparison to those which take these variables into consideration $(24,25)$.

The examination of interleukins is limited and it does not have a common worldwide application to evaluate ESWL-induced inflammation. Moreover, specificity and sensitivity of the methods are discussed. Therefore, we suggest that further studies should be carried out.

\section{Conclusion}

According to our results, ESWL leads to an inflammatory process in the urinary tract and the inflammation continues to increase up to 14 days after procedure. To reduce inflammation caused by ESWL, the best method of treatment should be selected based on the patient's condition. As mentioned above, ESWL is extensively used as a non-invasive method in the treatment of urinary stones. But it may lead to complications for the patients as well as other treatment options. Further studies are needed to investigate on incidence, severity, and complications of ESWL-induced inflammation. Moreover, studies should be carried out to find a biomarker with high specificity and sensitivity to detect this type of inflammation.

\section{Limitations of the study}

Low proportion of patients is a limitation of our study. We suggest larger investigation on investigation of inflammatory biomarkers in patients underwent ESWL.

\section{Acknowledgments}

The authors would like to thank the vice-chancellor of Zahedan University of Medical Sciences for their financial support of the study. We would also like to thank Mrs. Saiede Mahdipour from Bu'Ali hospital of Zahedan for her contribution to the data collection.

\section{Authors' contribution}

All authors contributed to design of the research. MRC, FF and MJ conducted the research. JD performed the statistical analysis and aided in interpretation of data. AZ drafted the manuscript. SM, AG and MB aided in the scientific revision of the manuscript. All authors read and approved the final manuscript.

\section{Conflicts of interest}

The authors declared no competing interests.

\section{Ethical considerations}

Ethical issues (including plagiarism, data fabrication, double publication) have been completely observed by authors.

\section{Funding/Support}

This study extracted from M.D thesis of Mohsen Rajabnia Chenari which was supported by the grant of chancellor for research and technology, Zahedan University of Medical Sciences.

\section{References}

1. Akin Y, Yucel S, Danisman A, Erdogu T, Baykara M. The impact of metabolic risk management on recurrence of urinary stones. J Health Sci 2012;2:17-20. doi: 10.17532/ jhsci. 2012.58

2. Landau E, Shenfeld O, Hardak B, Shapiro A, Meretyk S, Katz G, et al. Extracorporeal shock wave lithotripsy in prepubertal children: 22-years experience at a single institution with a single lithotripter. J Urol. 2009;182:183539. doi: 10.1016/j.juro.2009.04.084.

3. Skolarikos A, Alivizatos G, Rosette J. Extracorporeal shock wave lithotripsy 25 years later: complications and their prevention. Eur Urol. 2006;50:981-90. doi: 10.1016/j. eururo.2006.01.045.

4. Egilmez T, Ilteris M, Gonen M, Kilinc F, Goren R, Ozkardes $\mathrm{H}$, et al. Efficacy and safety of a new-generation shockwave lithotripsy machine in the treatment of single renal or ureteral stones: Experience with 2670 patients. J Endourol. 2007;21:23-27. doi: 10.1089/end.2006.0174.

5. Tabasi K, Haghighi M. Uretroscopic and Extracorporeal shock wave lithotripsy for rather large renal pelvis calculi. Urol J. 2007;4:221-25.

6. Paterson R, Lifshitz D, Kuo R, Siqueira TM Jr, Lingeman JE. Shock wave lithotripsy monotherapy for renal calculi. Int Braz J Urol. 2002;28:291-301.

7. Ghalayini I, Al-Ghazo M, Khader Y. Evaluation of emergency extracorporeal shock wave lithotripsy for obstructing ureteral stones. Int Braz J Urol. 2008;34:433-40.

8. Slavkovic A, Rodovanovic $M$, Vlaikovic $M$, et al. Extracorporeal shock wave lithotripsy in the management of pediatric urolithiasis. Urol Res. 2006;34:315-20. doi: 10.1007/s00240-006-0062-4.

9. Abdurrahman O, Iker Y. Extracorporeal shock wave lithotripsy of renal pelvis stones with PCK stonelith lithoteiper. Int Urol Nephrol. 2005;37:9-11. doi: 10.1007/ s11255-004-6085-2.

10. Dogan H, Tekgul S. Management of pediatric disease. Curr Urol Rep. 2007;8:163-73. doi: 10.1007/s11934-007-0067-8.

11. D’Addessi A, Vittori M, Racioppi M, Pinto F, Sacco E, Bassi P. Complications of extracorporeal shock wave lithotripsy for urinary stones: to know and to manage them - a review. ScientificWorldJournal. 2012;2012:619820. doi:10.1100/2012/619820.

12. Goktas C, Coskun A, Bicik Z. Evaluating ESWL-induced renal injury based on urinary TNF-a, IL-1a, and IL-6 levels. Urol Res. 2012;40:569-73. doi: 10.1007/s00240-012-0467-1.

13. Sarica K, Yencilek F. Prevention of shockwave induced functional and morphological alterations: an overview. Arch Ital Urol Androl. 2008;80:27-33.

14. Clark D, Connors B, Evan A, Willis LR, Handa RK, Gao S. Localization of renal oxidative stress and inflammatory response after lithotripsy. BJU Int. 2009;103:1562-68. doi: 10.1111/j.1464-410X.2008.08260.x.

15. Rieder J, Nisbet A, Lesser T, Franke EI, Brusky JP, Parekh AR, et al. IL-6 does not predict current urolithiasis in stone formers. J Endourol 2008;22:2373-75. doi: 10.1089/ 
end.2008.9702.

16. Pehlivan M, Coskun A, Zengin A. Does L-carnitine increase serum TNF-a and IGF-1 during liver regeneration in the rat? Turk J Med Sci. 2009;39:875-80.

17. Hoppe B, Kemper M. Diagnostic examination of the child with urolithiasis or nephrocalcinosis. Pediatr Nephrol. 2010;25:403-13. doi: 10.1007/s00467-008-1073-X.

18. Castle S, Cooperberg M, sadetsky N, Eisner BH, Stoller ML. Adequacy of a single 24-hour urine collection for metabolic evaluation of recurrent nephrolithiasis. J Urol. 2010;184:579-83. doi: 10.1016/j.juro.2010.03.129.

19. Lu J, Sun X, He L, Wang Y. Efficacy of Extracorporeal shock wave lithotripsy for ureteral stones in children. Pediatr Surg Int. 2009;25:1109-12. doi: 10.1007/s00383-009-2489-5.

20. Erden A, Artukoglu F, Gozacan A, Ozgen S. Comparison of propofol/fentanyl and Ketamine anesthesia in children during Extracorporeal shockwave lithotripsy. Saudi Med J.
2007;28:364-68.

21. Jalbani M, Deenari R, Abro M. Extracorporeal shock wave lithotripsy (ESWL) in children. Medical Channel. 2010;16:78-80.

22. Dundar M, Kocak I, Yenisey C, Serter M, Ozeren B. Urinary and serum cytokine levels in patients under SWL. Braz J Urol. 2001;27:495-99.

23. Ghalayini I, Al-Ghazo M, Khader Y. Evaluation of emergency extracorporeal shock wave lithotripsy for obstructing ureteral stones. Int Braz J Urol. 2008;34:433-40.

24. Majidpour H. Extracorporeal shock wave lithotripsy: efficacy and complications, 1994-2000 (Persian). Kordestan Med Univ J. 2002;5:4-8.

25. Singh O, Gupta S, Girish G, Aggarwal G, Mathur RK. Influence of prognostic factors on the outcome of extracorporeal shock wave lithotripsy in upper urinary tract stone disease. Nephrol Urol Month. 2010;2:476-480.

Copyright $\odot 2017$ The Author(s); Published by Nickan Research Institute. This is an open-access article distributed under the terms of the Creative Commons Attribution License (http://creativecommons.org/licenses/by/4.0), which permits unrestricted use, distribution, and reproduction in any medium, provided the original work is properly cited. 